\title{
Fate of Abstracts Presented at the First International Congress of Nephrology and Urology, Tehran, Iran, 2015
}

\author{
Seyed-Mostafa Hosseini-Zijoud, ${ }^{1}$ Farnaz Barzi, ${ }^{2}$ Aidin Lotfiazar, ${ }^{1}$ and Behzad Einollahi ${ }^{1,}$ \\ ${ }^{1}$ Nephrology and Urology Research Center, Baqiyatallah University of Medical Sciences, Tehran, IR Iran \\ ${ }^{2}$ Department of Nephrology, Imam Hossein Hospital, Shahid Beheshti University of Medical Sciences, Tehran, IR Iran \\ "Corresponding author: Behzad Einollahi, Nephrology and Urology Research Center, Ground Floor of Baqiyatallah Hospital, Mollasadra Ave., Vanak Sq., P.O. Box: 193955487, \\ Tehran, IR Iran. Tel: +98-2181262073, Fax: +98-2188067114, E-mail: behzad.einollahi@gmail.com
}

Received 2016 September 24; Accepted 2016 October 14.

\begin{abstract}
Objectives: The publication rate of abstracts presented at a scientific congress is considered as an indicator of congress's scientific quality. This rate is in range of $11 \%$ to $78 \%$ with an average of $45 \%$ in international medical congresses. The current survey aimed to determine the publication rate of the presented abstracts at the first international congress of nephrology and urology (ICNU) in 2015.

Methods: Data of oral and poster presentations including abstracts' titles and authors were gathered from the proceeding of the first ICNU, Tehran, Iran, 2015. The presented abstracts were searched in Scopus, PubMed, and ISC (for Persian language published papers). All the abstracts were categorized based on presentation type (oral or poster presentation), topic, study type and design, publication status, time interval between the presentation and the publication date, and the journal publishing the full text of the abstracts. Statistical analysis was done by SPSS (version 18, SPSS Inc., Chicago, IL, USA).

Results: The total number of abstracts accepted at the first ICNU was 210 ( 63 as oral and 147 as poster). The results showed that 49 out of 210 abstracts were published as full-text articles in indexed journals, giving the overall publication rate of $23.3 \%$. 6 out of 49 published papers were in Persian Language. In this survey, the rate of publication was $41.3 \%$ for oral presentations. The abstracts of prospective studies and original articles were more likely to be published in journals. The median time to publication was 5.3 months (range 1 - 12 months).

Conclusions: Novel ideas and innovative approaches were discussed at the first ICNU, Tehran, Iran, 2015. The 23.3\% publication rate found in the current study was lower than the mean publication rate of previous medical congresses. If the presented abstracts in a congress are not published as papers to be available to all, it would be waste of effort and time.
\end{abstract}

Keywords: Publication Rate, Abstract, International Congress of Nephrology and Urology (ICNU), Oral Presentation

\section{Background}

There are two main ways to share a scientific content. One of them is to provide it as a poster or oral presentation at a scientific conference and the other way is to publish it in a scientific, valid journal. The most recent science presented at prestigious congresses is very valuable for researchers and scientists, and it can be considered as a guide for further studies. On the other hand, presenting a scientific content at a congress makes it available to only a limited number of researchers and scientists; therefore, for making the scientific content available to more scientific audience, it should be published in a scientific journal. The publication of presented abstracts in a congress as full text articles could increase the credibility of the article and also enrich the scientific literature $(1,2)$.

The publication of a study in a scientific and peerreviewed journal is considered as a critical parameter in determining the credibility of that study. It is the best way to share information gained in a research study and increase the latter's incorporation into the scientific debate. Considering that the selection process for publishing an article in journals is stringent due to the peer-review process, only a limited number of abstracts will be published in prestigious peer-reviewed international journals. Therefore, the publication rate of presented abstracts at a conference is defined as an index for determining the conference's scientific quality $(2,3)$. The abstract publication rate in a variety of medical specialties demonstrated a broad range of 8.5 to $78 \%$ in literature review $(4,5)$. It is known that low publication rates of abstracts may have several reasons, most notably is the lack of time stated by researchers for preparation and submission of a full-text article. Also, it is possible that one does not submit a fulltext article for publication to a journal because his/her obtained results are not satisfactory or he/she has a problematic relationship with co-authors or has difficulty in selecting the appropriate journal (6-9).

The nephrology and urology research center affiliated

Copyright (c) 2017, Nephrology and Urology Research Center. This is an open-access article distributed under the terms of the Creative Commons 
to Baqiyatallah University of Medical Sciences, Tehran, Iran, organizes a biannual congress entitled international congress of nephrology and urology (ICNU). The congress attracts many researchers, especially nephrologists and urologists, from Iran and the rest of the world. The first ICNU was held in Razi convention center in Tehran on 10 - 12 June 2015.

To best of our knowledge, there is not any survey assessing the publication rate of presented abstracts at a national or international congress in Iran.

The current survey should be considered as the first study in this field in Iran. It aimed to determine the publication rate of presented abstracts as poster or oral presentation at the first ICNU in Iran, 2015, as full text articles in prestigious journals.

\section{Methods}

The first ICNU was held in Razi convention center in Tehran on 10 - 12 June 2015. The titles of the presented abstracts were collected from the proceeding of the congress (www.icnu.ir). In this study, all posters and oral presentations were included, and the content presented by guest speakers and also those presented in panel sessions for educational purposes were excluded.

The rate of publication in scientific journals was determined by searching databases including PubMed (http://www.ncbi.nlm.nih.gov/pubmed/) and Scopus (https://www.scopus.com/) as the largest abstract and citation databases of peer-reviewed journals. Moreover, ISC (http://www.isc.gov.ir/Default.aspx?lan=en) was searched for published papers in Persian Language scientific journals. The search was conducted until June 31, 2016. Two authors (S.M.H.Z and B.E) performed independently the search using the abstract's title in combination with the first author's name as search terms. If the first try was not successful, another search was conducted using the second author name, affiliation, and some main keywords. To confirm the matching, presented abstract in the proceeding and published article in journals were compared in terms of content.

All the presented abstracts were categorized based on presentation type (oral or poster presentation), study type (original research, review article, or case report), study design for original research (prospective, retrospective, or experimental), subspecialty (hemodialysis, transplantation, stones, kidney disease, prostate cancer, and so on) as well as time interval between presentation and publication (in months). Also, information of journal indexing (Web of Science or not) and journal names publishing the articles was also recorded.
It is noticeable to mention that, the presented abstracts published prior to the congress date were excluded from calculating the publication rates.

\subsection{Statistical Analysis}

Data were analyzed by SPSS software (version 18, SPSS Inc., Chicago, IL, USA). Quantitative variables were presented as mean \pm standard deviation (S.D.) and qualitative variables expressed as the frequency and percentage. Chisquare test was used to compare proportional values. Significance level was considered as p-value less than 0.05 .

\subsection{Ethical Consideration}

The official approval for access to available data in the proceeding was gained from the chairman and executive committee of the first ICNU, Teharn, Iran, 2015.

\section{Results}

A total of 210 abstracts (63 oral communications (30\%) and 147 posters (70\%)) were presented at the first ICNU, Teharn, Iran, in 2015.

The presented abstracts were mainly from original researches $(\mathrm{n}=164 ; 78.1 \%)$, followed by review articles $(\mathrm{n}=34$, $16.2 \%)$ and case reports $(n=12,5.7 \%)$.

In terms of study design, the frequency of prospective studies was 151 (71.9\%), the frequency of experimental studies was $34(16.2 \%)$, and the frequency of retrospective studies was 25 (11.9\%). Other characteristics of the presented abstracts are summarized in Table 1.

In total, 49 out of 210 abstracts were published in indexed journals. Therefore, the overall publication rate was $23.3 \%$ at the time of our search. In addition, 12 studies had been published before the congress date; thus, they were excluded from the calculation of publication rate.

The analysis of publication rate according to the type of presentation demonstrated that the rate of publication was $41.3 \%$ for oral presentations and $15.6 \%$ for poster sessions. These findings show that the publication rate was significantly higher in oral presentations than poster presentations $(\mathrm{P}=0.0001)$ (Table 2$)$.

Regarding the publication type, 41(25\%), 6 (17.6\%), and $2(16.6 \%)$ published abstracts were original articles, review articles, and case reports, respectively. These differences were not statistically significance $(P=0.51)$ (Table 3 ).

Publication rates based on study design were as follows: prospective studies: $25.2 \%$ (38 out of 151), retrospective studies: $16 \%$ (4 out of 25 ), and experimental studies: $20.6 \%$ (7 out of 34$)(\mathrm{P}=0.31)$ (Table 4 ).

The published abstracts were also classified based on subspecialty. The three most common subspecialties 
Table 1. Characteristics of the Presented Abstracts at the First ICNU $(\mathrm{n}=210)$.

\begin{tabular}{|c|c|}
\hline Type of Presentation & No. (\%) \\
\hline Oral & $63(30)$ \\
\hline Poster & $147(70)$ \\
\hline \multicolumn{2}{|l|}{ Type of Study } \\
\hline Original research & $164(78.1)$ \\
\hline Review article & $34(16.2)$ \\
\hline Case reports & $12(5.7)$ \\
\hline \multicolumn{2}{|l|}{ Study Design } \\
\hline Prospective & $151(71.9)$ \\
\hline Retrospective & $25(11.9)$ \\
\hline Experimental & $34(16.2)$ \\
\hline \multicolumn{2}{|l|}{ Subspecialty } \\
\hline Hemodialysis & $60(28.5)$ \\
\hline Kidney diseases & $58(27.7)$ \\
\hline Transplantation & $31(14.7)$ \\
\hline Cancer & $25(11.9)$ \\
\hline Stones & $17(8.1)$ \\
\hline Others & $19(9.1)$ \\
\hline
\end{tabular}

Table 2. Publication Rates Based on Presentation Type at the First ICNU

\begin{tabular}{lccc}
\hline $\begin{array}{l}\text { Type of } \\
\text { presentation }\end{array}$ & $\begin{array}{c}\text { No. of } \\
\text { Abstracts }\end{array}$ & $\begin{array}{c}\text { No. of } \\
\text { Published } \\
\text { Papers }\end{array}$ & $\begin{array}{c}\text { Publication } \\
\text { Rate, \% }\end{array}$ \\
\hline Oral & 63 & 26 & 41.3 \\
Poster & 147 & 23 & 15.6 \\
\hline
\end{tabular}

${ }^{\mathrm{a}} \mathrm{P}=0.0001$

Table 3. Publication Rates Based on Study Type at the First ICNU

\begin{tabular}{lccc}
\hline Study & $\begin{array}{c}\text { No. of } \\
\text { Abstracts }\end{array}$ & $\begin{array}{c}\text { No. of } \\
\text { Published } \\
\text { Papers }\end{array}$ & $\begin{array}{c}\text { Publication } \\
\text { Rate, \% }\end{array}$ \\
\hline $\begin{array}{l}\text { Original } \\
\text { article }\end{array}$ & 164 & 41 & 25 \\
Review article & 34 & 6 & 17.6 \\
\hline Case reports & 12 & 2 & 16.6 \\
\hline
\end{tabular}

${ }^{\mathrm{a}} \mathrm{P}=0.51$.

were transplantation (29\%), kidney diseases (25.9\%), and hemodialysis (23.3\%) (Table 5).

The three most frequently preferred journals were Journal of Nephropathology, Iranian journal of kidney diseases, and nephro-urology monthly (Table 6).

Investigations showed that 39 (18.4\%) of published ab-
Table 4. Publication Rates Based on Study Design of Presented Abstracts at the First $\mathrm{ICNU}^{\mathrm{a}}$

\begin{tabular}{lccc}
\hline Study & $\begin{array}{c}\text { No. of } \\
\text { Abstracts }\end{array}$ & $\begin{array}{c}\text { No. of } \\
\text { Published } \\
\text { Papers }\end{array}$ & $\begin{array}{c}\text { Publication } \\
\text { Rate, \% }\end{array}$ \\
\hline Prospective & 151 & 38 & 25.2 \\
\hline Retrospective & 25 & 4 & 16 \\
\hline Experimental & 34 & 7 & 20.6 \\
\hline${ }^{\mathrm{a}} \mathrm{P}=0.31$. & & & \\
\hline
\end{tabular}

Table 5. Publication Rates Based on Subspecialty of Presented Abstracts at the First $\mathrm{ICNU}^{\mathrm{a}}$

\begin{tabular}{lccc}
\hline Subspecialty & $\begin{array}{c}\text { No. of } \\
\text { Abstracts }\end{array}$ & $\begin{array}{c}\text { No. of } \\
\text { Published } \\
\text { Papers }\end{array}$ & $\begin{array}{c}\text { Publication } \\
\text { Rate, } \%\end{array}$ \\
\hline Hemodialysis & 60 & 14 & 23.3 \\
\hline $\begin{array}{l}\text { Kidney } \\
\text { diseases }\end{array}$ & 58 & 15 & 25.9 \\
\hline Transplantation & 31 & 9 & 29 \\
\hline Cancer & 25 & 4 & 16 \\
\hline Stones & 17 & 4 & 23.5 \\
\hline Others & 19 & 3 & 15.8 \\
\hline
\end{tabular}

${ }^{\mathrm{a}} \mathrm{P}=0.25$.

Table 6. Distribution of Publications in Journals $(n=49)$

\begin{tabular}{lc}
\hline Journals & Published Abstracts, No. (\%) \\
\hline Nephro-Urology Monthly & $5(10.2)$ \\
\hline Renal Failure & $4(8.2)$ \\
\hline Journal of Nephropathology & $8(16.3)$ \\
\hline Iranian Journal of Kidney Diseases & $5(10.2)$ \\
\hline Journal of Renal Injury Prevention & $3(6.1)$ \\
\hline Persian Language journals & $6(12.2)$ \\
\hline Others $^{\text {a }}$ & $18(36.8)$ \\
\hline
\end{tabular}

a 18 journals had 1 publication.

stracts are found in journals indexed in Thomson Reuters as SCI/SCI-expanded (Table 7).

Mean publication/acceptance time was 5.3 months (range 1-12 months) since the presentation of the papers in the conference. The abstracts published in journals before the launch of the first ICNU were excluded from the analysis and their time to publication was disregarded. 
Table 7. Indexing Status of Journals Publishing the Articles in ISI Thomson Reuters (SCI: Science Citation Index)

\begin{tabular}{lc}
\hline Index & Published Abstracts, No. (\%) \\
\hline Thomson Reuters (SCI or SCI-expanded) & $29(59.2)$ \\
ISC & $6(12.2)$ \\
other & $15(30.6)$ \\
\hline
\end{tabular}

\section{Discussion}

At the first international congress of nephrology and urology (ICNU), Teharn, Iran, in 2015, many novel research findings were presented. In the current survey, we assessed the publication rate of 210 presented abstracts in scientific journals. Our results showed that the publication rate in peer-reviewed journals within 12 months following the conference was $23.3 \%$.

The publication rate for the first ICNU was lower than those for international relevant congresses held by the American urological association (AUA, 37.8\% - 55.0\%) (6, $8,10)$, European association of urology (EAU, 47.3\%) (11), British association of urological surgeons (BAUS, 31.6\%) (11), and ICS Meeting (61.6\%) (12). Also, the publication rate of the abstracts of three annual nephrology meetings (American society of nephrology (ASN), National kidney foundation (NKF), and European renal association (ERA)) was $42 \%$ (13), which was higher than the rate found in our study. However, this low rate may be due to the exclusion of articles published before the date of the first ICNU.

The wide variation of publication rates for different international congresses may be related to the quality and quantity of the total presented abstracts $(8,14)$. Weber et al. (9) and Hoag et al. (6) declared that the more serious, time-consuming peer-review process in an international peer-reviewed journal in comparison with scientific congresses can lead to the reduction of the publication rate of abstracts in journals.

Although the publication rate in the case of ICNU is lower than the rates for other urology or nephrology congresses $(6,8,10-13,15)$, it was relatively higher than the publication rates of the abstracts presented at congresses held in the Middle East countries, such as the 22nd Turkish National Urology Congress by the rate of $10.8 \%$ (7).

To the best of our knowledge, the publication rate of presented abstracts in national or international congresses on Nephrology, Urology, or other medical specialties has not been investigated in Iran; thus, we cannot compare our findings with those of previous works within the country.

Ideally, abstracts presented at a scientific congress should be followed by the publication of its full-text in a prestigious journal. There are some reasons for the fulltext publication. First, the main new findings and useful data should be delivered to audience other than those participating in the congress. The audiences usually are specialists in the fields relevant to the congress from different parts of the world. Second, abstracts presented alone are normally associated with defects because the reliability and validity of these studies are not fully evaluated and peer-reviewed by the scientific committee of congresses. Third, according to the word limitation for abstracts, all information is not possibly presented in the proceeding of a congress. Therefore, additional information should be available to the audience in a full-text article published in journals. Balasubramanian et al. indicate minor inconsistencies in $86 \%$ and major inconsistencies in $69 \%$ of presented abstracts in comparison with full publications (16). This suggests that data of the presented abstracts can be inaccurate to a considerable extent.

It is reported that less than half of the abstracts presented at a medical congress are published in journals (17). There are several potential reasons in a multiplex approach, including lack of time, funds or other resources to prepare full-text article, low priority, problems with authorship, low quality of methodology, existence of other published reports, mistakes in journal selection, rejection of submitted paper, and unsatisfactory results $(9,18)$.

In the current investigation, it was found that the orally presented abstracts were more likely to be published in journals. Consistently, other similar investigations have also demonstrated that the publication rate was comparatively higher for oral presentations (15). Dossett et al. (19) and Beker-Acay et al. (4) asserted that oral presentations have significantly greater chance to be published in journals. It may be related to higher quality standards of both reviewers and presenters for oral presentations than poster presentations.

The publication rate of abstracts presented at any congress represents the scientific quality of the congress. In the current survey, the publication rate was higher for original studies than other study types. Hence, we should motivate researches and scientists to conduct original studies rather than review articles or case reports. Moreover, it is recommended that the scientific committee of congresses accept papers more carefully, because publication of case reports in journals is extremely difficult.

In the current study, the publication rate of prospective studies was the highest, which is similar to the findings of Beker-Acay et al. indicating a higher publication rate for prospective studies (4). In contrast, Yoon et al. reported higher publication rates for retrospective studies (20).

The current findings showed that some fields of inves- 
tigation have greater chance to publish. Abstracts in the field of transplantation, kidney diseases, and hemodialysis contributed mostly to the published papers in indexed journals. 59.2\% of journals publishing the abstracts were indexed in Thomson Reuters (SCI or SCI-expanded).

Additionally, of 49 abstracts published as full-text articles, $5(10.2 \%)$ were published by the Nephro-Urology Monthly, which is the official journal of the Nephrology Urology Research Center. The Nephro-Urology Monthly is published bimonthly and provides an essential resource for researchers and clinicians around the world.

At the first ICNU, the time interval between abstract presentation at the congress and publication in an indexed journal was 5.3 months (range 1-12 months). This median time to publication was lower than those recorded in previous studies $(21,22)$. In the previous investigations, search for published articles was conducted two years after the congress $(4,6,8)$, while this time was 12 months for the current survey. Therefore, it is possible that most of the presented abstracts at the first ICNU had not been submitted to any journal, which can explain the low publication rate.

With regard to the relatively low publication rate of abstracts presented at the first ICNU compared to American and European scientific congresses $(6,8,10-13,15)$, it is reasonable to motivate researchers to convert their abstracts into full-text articles. To increase the publication rate of abstracts and improve the scientific quality of a congress, referees and scientific committees should be encouraged to act more selectively in accepting the presentations. Additional approaches should be implemented to improve the standards and quality of abstracts presented at the ICNU for future sessions. Further research should focus on overcoming obstacles to the publication in journals.

\subsection{Limitations}

There are some limitations for the present study. One of them is that we omitted articles published before the date of the congress in the final analysis of data. Also, due to the occurrence of potential human errors, two independent researchers conducted review of the findings. Also, time interval was short (12 months) between the first ICNU and the date of conducting the search for published articles. By extending the time interval, the publication rate may increase.

\subsection{Conclusions}

In conclusion, the overall publication rate of abstracts presented at the first ICNU was low compared to other similar nephrology or urology congresses held in America and Europe. However, this publication rate was higher than those related to other congresses held in Middle East countries. These findings indicate that the first ICNU has still long way to reach standard levels and acceptable scientific quality. It is suggested for the scientific committee acting more carefully in the selection of abstracts to improve the publication rate of abstracts as well as the scientific quality of the ICNU.

\section{Acknowledgments}

The authors thank chairman and central executive committee of the first International congress of nephrology and urology, Teharn, Iran, 2015, for their technical assistance. The authors also gratefully acknowledge the cooperation of John W Pickering in preparation of this manuscript.

\section{Footnotes}

Disclosure of Interest: Prof. Einollahi is the chairman of the first international congress of nephrology and urology (ICNU), 2015, and is editor-in-chief of nephro-urology monthly as the official journal of the nephrology urology research center.

Financial Disclosure: The authors declare that this study has received no financial support.

\section{References}

1. Peng PH, Wasserman JM, Rosenfeld RM. Factors influencing publication of abstracts presented at the AAO-HNS Annual Meeting. Otolaryngol Head Neck Surg. 2006;135(2):197-203. doi: 10.1016/j.otohns.2006.04.006. [PubMed: 16890067].

2. Sawatsky AP, Beckman TJ, Edakkanambeth Varayil J, Mandrekar JN, Reed DA, Wang AT. Association Between Study Quality and Publication Rates of Medical Education Abstracts Presented at the Society of General Internal Medicine Annual Meeting. J Gen Intern Med. 2015;30(8):1172-7. doi: 10.1007/s11606-015-3269-7. [PubMed: 25814265].

3. van der Steen LP, Hage JJ, Loonen MP, Kon M. Full publication of papers presented at the 1995 through 1999 European Association of Plastic Surgeons annual scientific meetings: a systemic bibliometric analysis. Plast Reconstr Surg. 2004;114(1):113-20. [PubMed:15220578].

4. Beker-Acay M, Fidan N, Unlu E, Katirag A, Ulker H, Acay A, et al. The fate of abstracts presented at Turkish national radiology congresses in 2010-2012. Diagn Interv Radiol. 2015;21(4):322-6. doi: 10.5152/dir.2015.14451. [PubMed: 26133322].

5. Tambuscio S, Boghossian E, Sauvageau A. From abstract to publication: the fate of research presented at an annual forensic meeting. J Forensic Sci. 2010;55(6):1494-8. doi: 10.1111/j.1556-4029.2010.01504.X. [PubMed: 20666914].

6. Hoag CC, Elterman DS, Macneily AE. Abstracts presented at the American Urological Association Annual Meeting: determinants of subsequent peer reviewed publication. J Urol. 2006;176(6 Pt 1):2624-9. doi: 10.1016/j.juro.2006.08.021. [PubMed: 17085176] discussion 2629.

7. Kocaaslan R, Kayali Y, Tok A, Tepeler A. Publication rates of fulltext journal articles converted from abstracts presented during the 22(nd) Turkish National Urology Congress. Turk J Urol. 2016;42(1):1620. doi: 10.5152/tud.2016.75233. [PubMed: 27011876]. 
8. Ng L, Hersey K, Fleshner N. Publication rate of abstracts presented at the annual meeting of the American Urological Association. BJU Int. 2004;94(1):79-81. doi: 10.1111/j.1464-410X.2004.04905.x. [PubMed: 15217436].

9. Weber EJ, Callaham ML, Wears RL, Barton C, Young G. Unpublished research from a medical specialty meeting: why investigators fail to publish. JAMA. 1998;280(3):257-9. [PubMed: 9676674].

10. Smith WA, Cancel QV, Tseng TY, Sultan S, Vieweg J, Dahm P. Factors associated with the full publication of studies presented in abstract form at the annual meeting of the American Urological Association. J Urol. 2007;177(3):1084-8. doi: 10.1016/j.juro.2006.10.029. [PubMed: 17296415] discussion 1088-9.

11. Rao AR, Beatty JD, Laniado M, Motiwala HG, Karim OM. Publication rate of abstracts presented at the British Association of Urological Surgeons Annual Meeting. BJU Int. 2006;97(2):306-9. doi: 10.1111/j.1464-410X.2006.05863.x. [PubMed: 16430635].

12. Autorino R, Quarto G, Di Lorenzo G, De Sio M, Damiano R. Are abstracts presented at the EAU meeting followed by publication in peerreviewed journals? A critical analysis. Eur Urol. 2007;51(3):833-40. doi: 10.1016/j.eururo.2006.10.024. [PubMed:17084516] discussion 840.

13. Harel Z, Wald R, Juda A, Bell CM. Frequency and factors influencing publication of abstracts presented at three major nephrology meetings. Int Arch Med. 2011;4(1):40. doi: 10.1186/1755-7682-4-40. [PubMed: 22145917].

14. Rubin HR, Redelmeier DA, Wu AW, Steinberg EP. How reliable is peer review of scientific abstracts? Looking back at the 1991 Annual Meeting of the Society of General Internal Medicine. $J$ Gen Intern Med. 1993;8(5):255-8. [PubMed: 8505684].

15. Cartwright R, Khoo AK, Cardozo L. Publish or be damned? The fate of abstracts presented at the International Continence Society Meeting 2003. Neurourol Urodyn. 2007;26(2):154-7. doi: 10.1002/nau.20391.
[PubMed: 17252602].

16. Balasubramanian SP, Kumar ID, Wyld L, Reed MW. Publication of surgical abstracts in full text: a retrospective cohort study. Ann $R$ Coll Surg Engl. 2006;88(1):57-61. doi: 10.1308/003588406X82961. [PubMed: 16482660].

17. Scherer RW, Langenberg P, von Elm E. Full publication of results initially presented in abstracts. Cochrane Database Syst Rev. 2007(2):MR000005. doi: 10.1002/14651858.MR000005.pub3. [PubMed: 17443628].

18. Sprague S, Bhandari M, Devereaux PJ, Swiontkowski MF, Tornetta P3, Cook DJ, et al. Barriers to full-text publication following presentation of abstracts at annual orthopaedic meetings. J Bone Joint Surg Am. 2003;85-A(1):158-63. [PubMed: 12533587].

19. Dossett LA, Fox EE, del Junco DJ, Zaydfudim V, Kauffmann R, Shelton J, et al. Don't forget the posters! Quality and content variables associated with accepted abstracts at a national trauma meeting. J Trauma Acute Care Surg. 2012;72(5):1429-34. doi:10.1097/TA.0b013e3182479c9b. [PubMed: 22673278].

20. Yoon PD, Chalasani V, Woo HH. Conversion rates of abstracts presented at the Urological Society of Australia and New Zealand (USANZ) Annual Scientific Meeting into full-text journal articles. BJU Int. 2012;110(4):485-9. doi: 10.1111/j.1464-410X.2011.10879.x. [PubMed: 22300438].

21. Chand V, Rosenfeldt FL, Pepe S. The publication rate and impact of abstracts presented at the Cardiac Society of Australia and New Zealand (1999-2005). Heart Lung Circ. 2008;17(5):375-9. doi: 10.1016/j.hlc.2008.02.005. [PubMed: 18514027].

22. Rollin L, Darmoni S, Caillard JF, Gehanno JF. Fate of abstracts presented at an International Commission on Occupational Health (ICOH) congress-followed by publication in peer-reviewed journals? Scand J Work Environ Health. 2009;35(6):461-5. [PubMed: 19851699]. 